This document is the accepted manuscript version of the following article:

Iyer, A. H. S., Mohanty, G., Stiller, K., Michler, J., \& Colliander, M. H. (2019). Microscale fracture of chromia scales. Materialia, 8, 100465 (9 pp.).

https://doi .org/10.1016/j.mt1a.2019.100465

\title{
Microscale fracture of chromia scales
}

Anand H.S. Iyer ${ }^{\mathrm{a}}$, Gaurav Mohanty ${ }^{\mathrm{b}, \mathrm{c}}$, Krystyna Stiller ${ }^{\mathrm{a}}$, Johann Michler ${ }^{\mathrm{c}}$, Magnus Hörnqvist Colliander ${ }^{\text {** }}$

a Department of Physics, Chalmers University of Technology, Gothenburg, Sweden - 41296.

b Materials Science and Environmental Engineering, Tampere University, 33014, Tampere, Finland

${ }^{c}$ Empa, Swiss Federal Laboratories for Materials Science and Technology, Laboratory for Mechanics of Materials and Nanostructures, Feuerwerkerstrasse 39, 3602 Thun, Switzerland *Corresponding author: magnus.colliander@chalmers.se

\begin{abstract}
Native protective oxide scales offer resistance against corrosion for high temperature materials, which often work in extreme conditions of varying mechanical and thermal loads. The integrity of such layers is of critical importance, since their damage can lead to significant reduction in material life. Mechanical data such as fracture strain and elastic modulus are required to include oxides in material life estimation models for high temperature materials, but there is lack of such data. Their thickness is in the $\mu \mathrm{m}$ range, which makes mechanical testing for property determination difficult. Here we present a micro-mechanical testing method, based on bending of micro-cantilevers produced by focused ion beam milling, capable of circumventing the limitations of conventional approaches. We apply this method to chromia thermally grown on pure chromium, and measure fracture strains at room and high temperatures $\left(600^{\circ} \mathrm{C}\right)$. The measured fracture strains were found to be higher at room temperature, due to a larger fraction of transgranular fracture. Surprisingly, a large fraction of transgranular fracture was seen even in the presence of stress concentrations at grain boundaries. Removal of the stress concentrations accentuated the propensity for transgranular cracking at room temperature. Realistic values of room temperature elastic modulus were
\end{abstract}


obtained as well. The observed mixed trans- and intergranular cracking points towards the need for dedicated investigations of both oxide grain boundary strength and cleavage resistance of single crystals in order to fully understand the failure mechanisms in thermally grown oxide scales.

Keywords: Micromechanics; fracture mechanisms; electron microscopy; oxide; chromia.

\section{Introduction}

High temperature materials, such as superalloys and high temperature steels, are often employed in extreme conditions where they experience a combination of severe mechanical loads at elevated temperatures in the presence of a corrosive environment. In such situations, they depend on the formation of a protective oxide scale for resistance against degradation. In the presence of fluctuating loads and temperatures during operation, the materials are subjected to thermo-mechanical fatigue (TMF), which has been extensively studied for these materials [1-3]. Oxide scales are generally brittle and such fluctuating thermal and/or mechanical loads can cause damage. Depending on the adhesion strength of the oxide scales, this can either lead to formation of through cracks or even spallation, thereby exposing the material to further oxidation [4]. Through cracks in oxide scales can act as fatigue crack initiation sites for the bulk material. Cruchley et al. [5] observed significant reduction in the fatigue life of Ni-base superalloy specimens subjected to pre-oxidation, compared to polished specimens. This was attributed to crack initiation from the oxide scale. Compressive dwells, both during isothermal high temperature fatigue [6] and during the hot part of TMF cycles [7], have been shown to reduce fatigue life since the oxide formed during compressive loads fractures in the subsequent tensile leg of the cycle, leading to rapid crack initiation in the material. Furthermore, oxidation at the crack tip can induce accelerated crack growth, 
causing fatigue crack growth rates at high temperatures to be an order higher in air than vacuum for superalloys such as Alloy 718 [8-12].

As the integrity of the protective oxide scales have a direct impact on the life of high temperature materials, it is necessary to include behaviour of the oxides in lifetime prediction models for improved reliability. Several models have been developed for describing the failure of oxide scales and the dependence of various parameters involved in their cracking with the aid of fracture mechanics [13-16]. Schütze et al. [17] developed an approach to a comprehensive oxide scale failure diagram based on fracture mechanics, which examines the various modes of failure in oxide scales. This has been applied in a simplified form by Rudolphi et al. $[18,19]$ and has been validated for oxide scales such as $\mathrm{NiO}, \mathrm{TiO}_{2}$ and $\mathrm{Fe}_{2} \mathrm{O}_{3}$. These models require input in the form of parameters such as failure strain, elastic modulus and physical defect size in order to describe the fracture behaviour of the oxide scales. Also, in the case of complex life assessment models on oxidation assisted crack growth [20], fracture strain and elastic modulus of oxides are key parameters. But, as has been pointed out by Schütze et al. [21], the required data regarding mechanical behaviour of oxides, specifically fracture properties, are still lacking.

Several methods have been developed in the past few decades to measure the elastic modulus and fracture strains of oxide scales. One of the earliest methods for measuring fracture strain by Hurst et al. [22] utilises the change in resonant frequency of a specimen during oxidation. A frequency drop during tensile loading observed with the help of dynamic frequency measurements indicated oxide scale failure and this was used as an estimate for the tensile fracture strains of oxide scales. Four-point bending tests on oxide scales have also been used to obtain both compressive and tensile fracture strains [23]. Specimens with oxide scale 
grown on them were subjected to bending, and acoustic emission was used to identify exact moments of oxide scale fracture. Nanoindentation is a powerful and direct technique which has been used to measure the hardness and elastic modulus of oxide scales. Tortorelli et al. [24-26] and Nicholls et al. [27] have worked extensively on the measurement of elastic modulus of different oxide scales at room and high temperatures using nanoindentation. Taper polishing methods on oxide scales have been used to assess the influence of substrate [25] and measurements on spalled oxide scales have been proposed to estimate the influence of residual stresses [26].

The aforementioned methods have mostly been used for measurements of thick oxide scales (several $\mu \mathrm{m}$ to tens of $\mu \mathrm{m}$ thick). Except for nanoindentation, the other methods provide only an indirect way of measuring hardness and elastic modulus. The influence of growth and residual stresses, and substrate influence have not been studied extensively since it is beyond the capabilities of these methods. This is critical, as pointed out by Nagl et al. [28] in the case of $\mathrm{NiO}$ and $\mathrm{Fe}_{2} \mathrm{O}_{3}$, where failure strains could be overestimated by a factor of two if residual stresses are not considered. Furthermore, in the case of many modern alloys, especially superalloys, the oxidation kinetics are slow and the thickness of oxide scales formed are in the sub- $\mu \mathrm{m}$ to $\mu \mathrm{m}$ range. The previously described methods fail to address the properties of oxide scales in this size range. Clearly, and as pointed out in [21], a new approach is necessary in order to determine these oxide properties in a direct manner so that the experimentally measured values could be used in the models. With the advent of focused ion beam (FIB) milling techniques, it became possible to manufacture specimens in the $\mu \mathrm{m}$ range with sufficient accuracy for mechanical testing at this scale, commonly referred to as micromechanical testing. Specimens of different geometries such as cantilevers [29-32], tensile specimens [33], micropillars [34-37], etc can be manufactured with precision using FIB and 
tested with the help of nanoindenters and micromanipulators. Micro-mechanical testing offers a unique tool to assess the response of thin surface layers, due to its ability to probe mechanical properties of specimens at $\mu \mathrm{m}$ length scales with high spatial resolution. This has been extensively utilised for numerous thin film and coating systems [38-41], but so far only a very limited number of studies have been performed on surface oxide scales [42-44] in order to estimate their fracture and elastic properties.

We have previously demonstrated a micro-cantilever bending method [44] for testing thermally grown oxide scales, which was capable of probing very thin $(<200 \mathrm{~nm})$ native oxides formed on a Ni-base superalloy. Interestingly, these scales showed evidence of pronounced plasticity at room temperature, presumably due to the presence of an outer spinel layer. Since micro-cantilever bending inevitably localizes the high tensile stresses on the upper surface, the properties of the underlying chromia layer could not be assessed. As chromia is the protective oxide for many high temperature materials, including superalloys, it is critical to further investigate its deformation and fracture properties. We apply the same approach as used in [44] in order to measure fracture strains and elastic modulus of pure chromia scales at both room and elevated temperatures. Interestingly, we observe a reduction in the fracture strain of chromia at $600{ }^{\circ} \mathrm{C}$ compared to room temperature. Examination of the fracture surfaces provided information regarding the fracture mechanism showing that, surprisingly, transgranular fracture was seen even in cases where stress concentrations at oxide grain boundaries were present. By comparing the fracture path with the crystallographic orientation of the oxide grains, the transgranular fracture was found to correlate well with the most probable cleavage planes. 


\section{Experimental methods}

\subsection{Isothermal exposure and oxide characterisation}

Pure chromium (99.97\% purity) samples were cut into coupon shaped specimens with dimensions of $15 \times 15 \times 2 \mathrm{~mm}$. The flat surfaces were mechanically polished with $\mathrm{SiC}$ paper up to 4000 grit followed by diamond polishing with 3 and $1 \mu \mathrm{m}$ diamond suspensions. The samples were thoroughly cleaned in an ultrasonic bath in acetone and ethanol. The isothermal exposures were conducted in an alumina tube furnace at $700{ }^{\circ} \mathrm{C}$ in a pure oxygen environment with gas flow rate of $150 \mathrm{ml} / \mathrm{min}$ for 480 hours. Two samples were oxidized for sake of comparison.

The oxidised specimen surfaces were imaged with JEOL 7800F Prime FEG scanning electron microscope (SEM) in order to obtain an overview of the oxide microstructure. Cross sections of the oxide layer were prepared with the help of focused ion beam (FIB) milling in a FEI Versa3D dual beam instrument, in order to estimate the thickness of the oxide layer. The oxide microstructure was examined with the help of electron transparent foils prepared by FIB milling using the lift-out technique. Scanning transmission electron microscopy (STEM) was performed in a Tescan GAIA3 FIB-SEM on the electron transparent foil of the oxide scale at a voltage of $30 \mathrm{kV}$ and $200 \mathrm{pA}$ current in high-resolution mode to obtain a fine spot size. The crystallographic orientations of the oxide grains were studied with the help of transmission Kikuchi diffraction (TKD) with an Oxford instruments NanoNordlys EBSD detector.

\subsection{Micro-cantilever preparation}

The oxidised specimens were cut with a low speed diamond saw and the cross sections were metallographically prepared manually by grinding using SiC papers up to 4000 grit size in 
order to provide a sharp edge for the preparation of micro-cantilevers using FIB milling. Compressive residual stresses of the order of $0.5-1.5 \mathrm{GPa}$ were present in the oxide scales (see supplementary material, section A) and, consequently, the previously developed cantilever geometry designed to circumvent residual stress effects of the oxides was used [44]. In short, it consists of a region about $3 \mu \mathrm{m}$ in length near the support where the metal is completely removed and the oxide is isolated, allowing the residual stresses in this region to completely relax. However, a significant amount of the metal substrate is left on the remaining part of the cantilever to avoid excessive bending from stress relaxation and allow suitable condition for the mechanical loading. The rough milling was performed with currents of 7, 3 and $1 \mathrm{nA}$, and finishing for the final geometry was done at a lower current of $100 \mathrm{pA}$ to reduce the effects of ion implantation. Figure 1(a) shows the schematic for the geometry of the micro-cantilever. For one set of cantilevers, the top surfaces were left untouched by FIB milling in order to avoid influence of Ga ion implantation and also to be representative of real conditions. However, a small portion near the free end is flattened with FIB from the side to facilitate the placement of indenter. These will be referred to as 'raw' micro-cantilevers from here on. The dimensions of the prepared cantilevers are measured from top and side view of SEM images. The height of the cantilever is measured as the average height in the isolated portion of the oxide (Figure 1(b)). Table S1 in the supplementary material lists the dimensions of the prepared raw micro-cantilevers. An additional set of micro-cantilevers was prepared by removing the surface roughness along the entire length through ion milling at low currents from the side in order to minimize gallium implantation. This set was prepared for experimentally determining the elastic modulus of the oxide layer. These will be referred to as 'flat' micro-cantilevers from here on. The dimensions of those micro-cantilevers are given in table $\mathrm{S} 2$ in the supplementary material. 

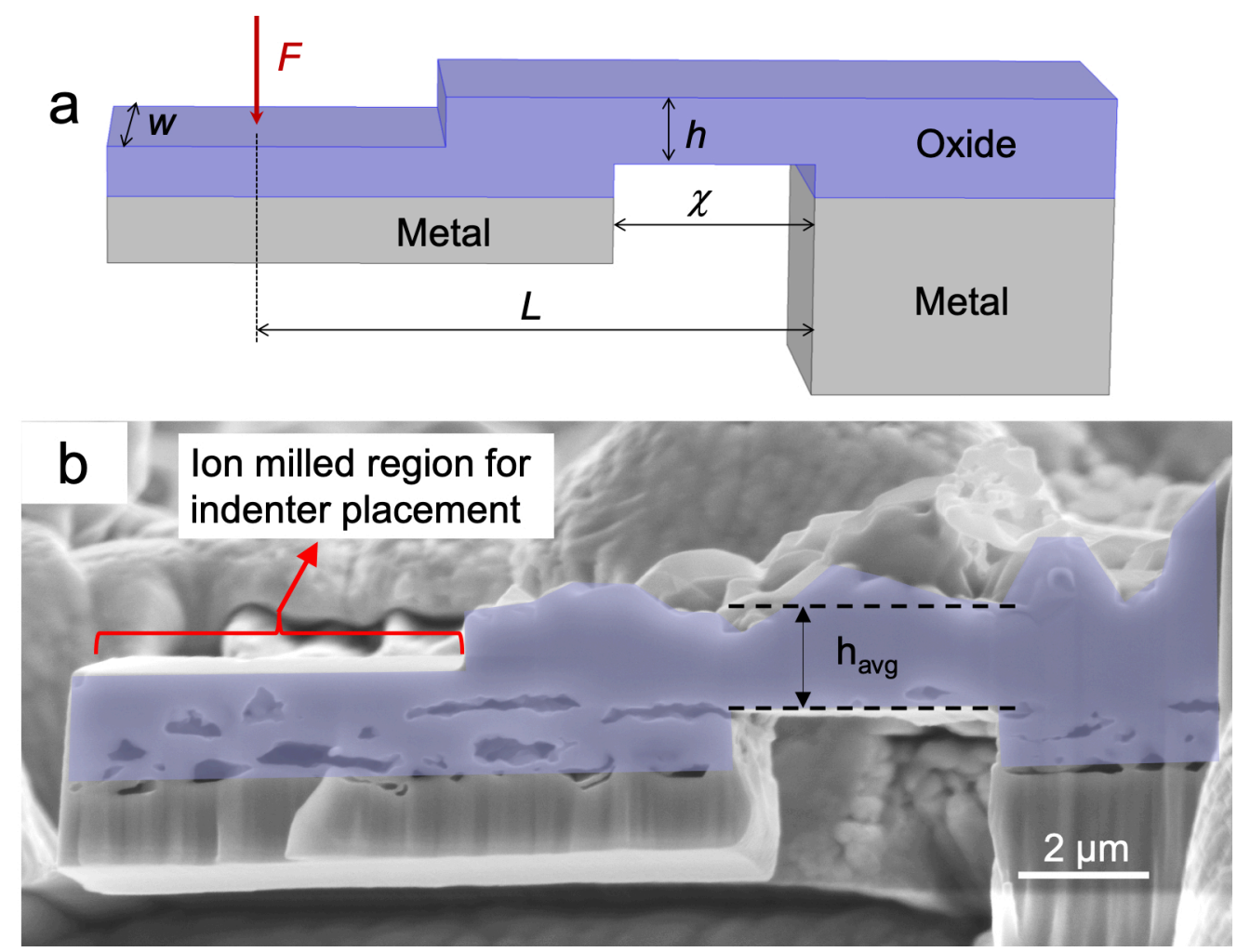

Figure 1: (a) Schematic of micro-cantilever showing different dimensions (b) SEM image showing geometry of micro-cantilever.

\subsection{Micro-cantilever bending tests}

All micro-cantilever bending tests were performed with an Alemnis in-situ nanoindenter (Alemnis AG, Switzerland) [45]. The raw micro-cantilevers were tested in a Zeiss DSM 962 SEM and the flat ones were tested in a Zeiss LEO55 FEG SEM. For the $600{ }^{\circ} \mathrm{C}$ tests, the high temperature module from Alemnis was used. The compact high temperature Alemnis setup employed independent tip and sample heating that enables iso-thermal matching of the two contacting bodies (tip apex, sample surface) to minimize thermal drift. The indenter frame is water-cooled to maintain the sensors and actuators from getting affected by the heat and for faster thermal stabilization times. Thermal drift rates were minimized using the protocols outlined previously [46,47]. A tungsten carbide cono-spherical indenter (Synton-MDP AG, Switzerland) with tip radius $\sim 1 \mu \mathrm{m}$ was used for the reported micro-bending tests of raw 
micro-cantilevers and a diamond tip of similar radius was utilised for testing of flat microcantilevers. The samples were mounted on a high temperature copper stub using a conductive high temperature cement (Aremco Pyroduct 597-A). Displacement controlled microcantilever bending tests were performed at room temperature (RT) and $600^{\circ} \mathrm{C}$ on the raw microcantilevers. Each testing cycle consisted of fixed periods of thermal load drift testing before and after the bending test. The load-displacement curves were corrected for the pre-existing load drift. The flat micro-cantilevers were initially subjected to small displacement tests (where repeated loading-unloading cycles with different load amplitudes where applied) in order to estimate the elastic modulus. This was followed by displacement-controlled fracture tests.

The oxide micro-cantilevers after testing were imaged in an SEM from the top and side to get a clear view of the crack. Some tested micro-cantilevers, which had not broken off completely, were carefully broken and removed with the help of a Kleindiek micromanipulator setup after the above imaging so that the fracture surfaces are visible. The samples were then imaged in a Zeiss LEO55 FEG SEM to obtain high resolution images of the fracture surfaces.

\section{Results}

\subsection{Oxide microstructure}

The isothermal exposure generated an oxide scale that was rough on the surface and consisted of a combination of small and large faceted grains (Figure 2(a)). The average thickness of the scale measured from FIB cross sections was $2.8 \pm 0.6 \mu \mathrm{m}$. STEM imaging on the oxide scale cross section showed grains of increasing size from the bottom of the scale to top (Figure 2(b)). The small grains close to the oxide metal interface have an average size of about 120 
nm, which have an equiaxed structure (Figure 2(c)). A homogenous layer of oxide grains of an average size of $1 \mu \mathrm{m}$ covers the whole surface, whereas some grains on the surface have grown larger (Figure 2(a) and (c)). TKD showed the appearance of a texture in the larger grains, which preferentially grow with the $c$-axis $(<0001>)$ perpendicular to the interface as seen from the inverse pole figure (IPF) map for the growth direction (Figure 2(d)). No such tendency is seen in the underlying fine-grained oxide, which shows a more random orientation distribution. Another feature visible from the images is the presence of porosity, both at the oxide metal interface and within the scale. Some dislocations are visible in the larger grains (arrows in Figure 2(b)). From the observed morphology of the oxide, it is clear that there will be significant stress concentrations at oxide grain boundaries in the case of the raw cantilevers. 

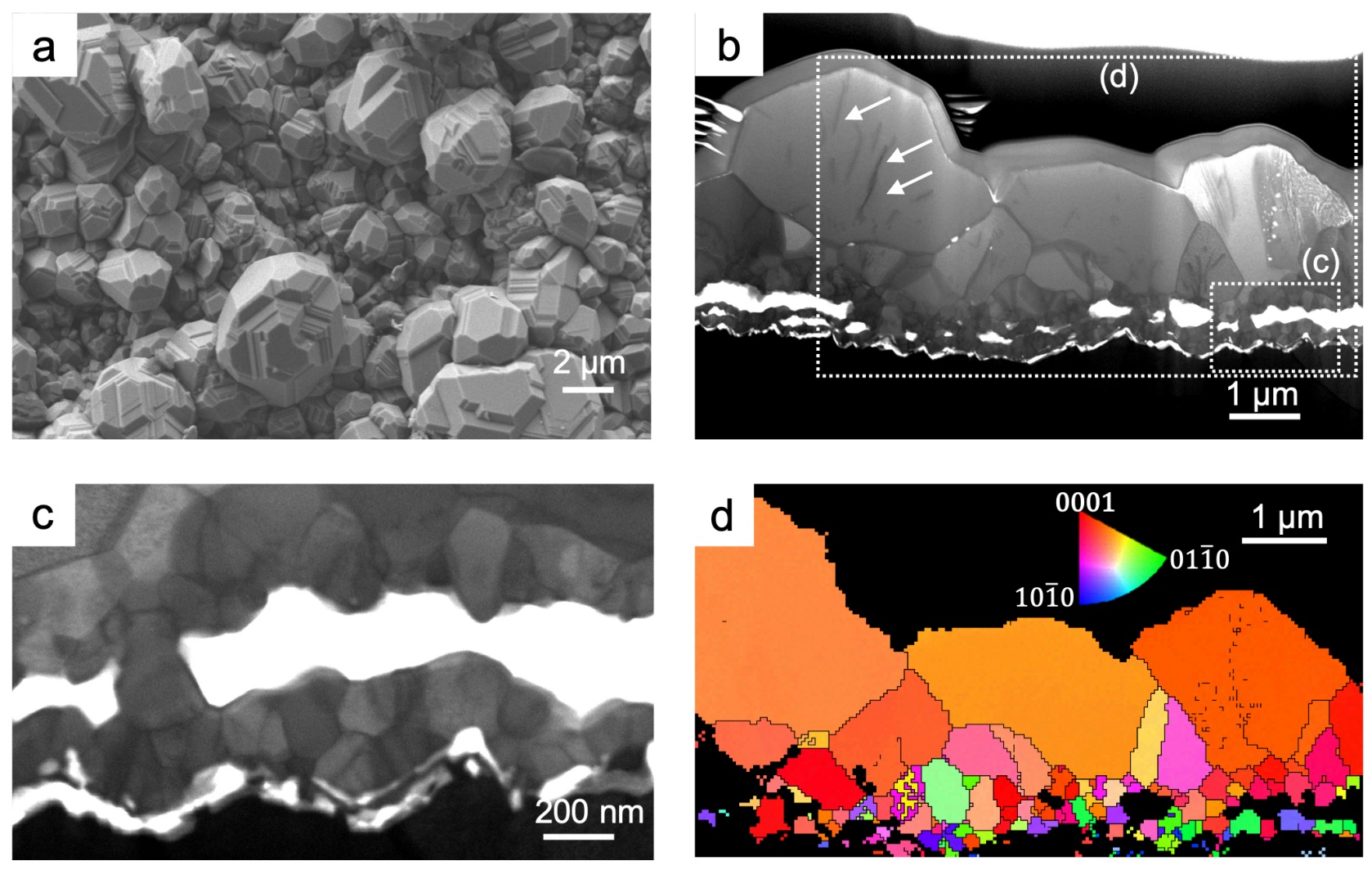

Figure 2: (a) SEM image of the oxide scale surface showing an underlying layer covering the entire surface, with occasional larger grains on top; (b) STEM bright field image of an oxide cross-section clearly showing porosity in the lower parts of the oxide; (c) shows STEM image of highlighted region from (b) with smaller grains; and (d) inverse pole figure map of region highlighted in (b) showing random orientations of the fine-grained underlying oxide and preferential $<0001>$ growth of the larger grains. 

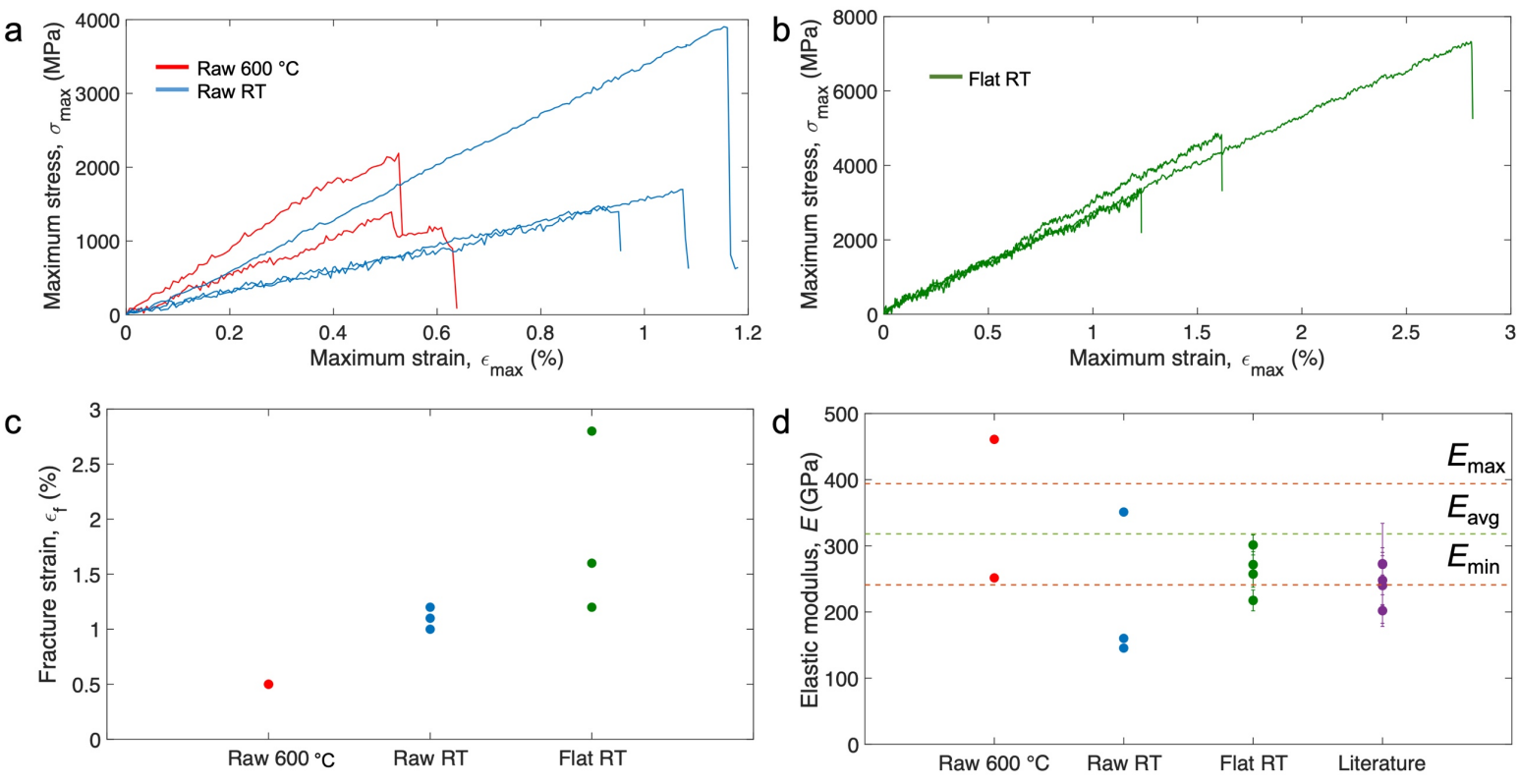

Figure 3: (a) Stress-strain curves for tested raw micro-cantilevers; (b) stress-strain curves from the fracture tests of flat micro-cantilevers; (c) comparison of the fracture strains; and (d) measured elastic modulus for different tested micro-cantilevers, including comparison with literature data $([25,27])$ and theoretical average modulus, $E_{\text {avg }}$, and upper and lower limits from elastic anisotropy, $E_{\max }$ and $E_{\min }$.

\subsection{Mechanical response}

The data obtained from the micro-cantilever bending tests is in the form of force $(F)$ and displacement $(\delta)$. As the $F-\delta$ response strongly depends on the cantilever geometry, a conversion to the corresponding (approximate) stress-strain curves were performed. There is a purely geometric relation (independent of material properties) between $F$ and the local maximum stress $\left(\sigma_{\max }\right)$, as well as between $\delta$ the local maximum strain $\left(\varepsilon_{\max }\right)$, which was utilised for the conversion. Generally, for simple prismatic beams, analytical formulas are used for this purpose but due to the complex geometry of the current micro-cantilevers, finite element modelling (FEM) was used to derive the geometrical constants. Due to surface roughness, an exact response cannot be calculated for the raw cantilevers, so an average 
height was used to create the FE model, neglecting the geometric stress concentrations arising from the scale morphology. The procedure is detailed in section B of the supplementary material. The geometric constants were derived individually for each tested cantilever and used to construct the stress-strain curves. Here it should be noted that the oxide and substrate were modelled using the same elastic material properties, meaning that the deformation at the supported end will not be accurately captured. However, this effect is small compared to other sources of uncertainty [44], in particular as the average moduli of chromium and chromia is not vastly different. Figure 3(a) shows the calculated $\sigma_{\max }-\varepsilon_{\max }$ curves for the raw microcantilevers. It can be noticed that the response is linear until fracture, implying elastic behaviour.

Despite converting to stress and strain, the data shows significant variation in slope (stiffness). This could be due to a number of factors such as surface roughness, porosities, oligo-crystalline nature of the oxide layer, anisotropic elasticity or a combination of these. On removal of surface roughness, the scatter in slope gets reduced, which can be seen from the stress-strain curves for the tested flat micro-cantilevers (Figure 3(b)). The fracture strains for the raw micro-cantilevers show a trend despite the scatter in the curves. It can be seen from figure 3(c) that the fracture strains ( $\varepsilon_{\mathrm{f}}$, defined as $\varepsilon_{\max }$ corresponding to the point of fracture) are close together for the same condition of testing in the case of raw micro-cantilevers (note that the data point for $600{ }^{\circ} \mathrm{C}$ in Figure 3(c) is actually two overlapping points). Somewhat surprisingly, the fracture strain at $600{ }^{\circ} \mathrm{C}$ is approximately half of that of the room temperature tests. The fracture strain obtained from flat micro-cantilevers show a larger scatter in comparison to the raw ones. The flat micro-cantilevers show larger fracture strains, which is expected due to the removal of the stress concentrations. Furthermore, the scatter in fracture strain is larger for the flat cantilevers, which, again, could be related to the absence of 
stress concentrations. The fracture in this case would be governed by statistical effect expected in case of ceramics (position of porosity, crystal size, etc), whereas for the raw micro-cantilevers, the stress concentrations play a major role. Details regarding the mechanism of cracking can be obtained by examination of the crack path and the fracture surface, which will be described later.

Elastic modulus estimations were performed by small displacement tests designed to obtain the linear response before fracture for the flat micro-cantilevers. It was possible to test four different micro-cantilevers, and Figure 3(d) shows the estimated elastic modulus from all the bending tests. Since the test value for each cantilever were derived as an average of multiple tests, it was also possible to estimate the experimental errors. The values obtained from fracture tests of raw micro-cantilevers ('Raw $600^{\circ} \mathrm{C}$ ' and 'Raw RT') have been included as well for sake of comparison. Some values from literature $[25,27]$ have been included in order to compare with the previous measurements attempted for the oxide. The values of the elastic modulus measured from the flat micro-cantilevers are in excellent agreement with the literature data, in spite of the large sensitivity to errors in geometry measurement inherent in the cantilever bending method for stiffness estimation. Furthermore, as the highly-stressed part of the micro-cantilevers only contains a small number of grains, and the elastic response of chromia is anisotropic, a large variation can be expected even in the case of perfect measurements of the geometry. The dotted lines in the figure refer to the calculated (polycrystalline Voigt) average $\left(E_{\mathrm{avg}}\right)$, maximum $\left(E_{\max }\right)$, and minimum $\left(E_{\min }\right)$ theoretical elastic modulus which were calculated from the stiffness matrix obtained from [48] using the online tool ELATE [49]. Details regarding elastic modulus evaluation is described in section $\mathrm{D}$ and theoretical calculations in section $\mathrm{E}$ of the supplementary material. The experimental values for the flat micro-cantilevers fall in the lower end of the estimated range, which is 
expected for two reasons: (i) the texture of the larger grains will place the basal planes parallel to the tensile axis, and the elastic modulus in the basal plane is relatively low; (ii) the presence of porosity reduces the load carrying area leading to larger displacements and lower estimated stiffness. The second point is also the likely reason behind the data point below the estimated lower bound. For the raw cantilevers tested at RT, one data point is significantly lower than expected, which could stem from the combined presence of porosity and strain localisation due to the surface stress concentrations. The largest discrepancy is the extremely high modulus $(\sim 460 \mathrm{GPa})$ measured in one of the raw cantilevers tested at $600{ }^{\circ} \mathrm{C}$. A probable explanation is the difficulty in estimation of the geometry of the micro-cantilever for calculations. When determining the average height, the cantilever is viewed edge on, providing only a $2 \mathrm{D}$ projection of the rough $3 \mathrm{D}$ surface. The roughness across the width of the cantilever is uncertain, which can lead to the underestimation of height, and overestimation of elastic modulus. As mentioned, cantilever bending is very sensitive to errors in the thickness, as the area moment of inertia scales inversely with the cube of the thickness.

\subsection{Fracture behaviour}

Figure 4 shows the side and top views for a raw micro-cantilever tested at $600{ }^{\circ} \mathrm{C}$. It can be seen from figure 4(b) that the crack starts between two grains on the surface and has stopped near a pore in the bottom layer of the oxide scale. From the top view of the crack (Figure 4(d)), it seems that the crack has propagated in an intergranular manner. Other microcantilevers tested under the same conditions exhibit features of cleavage fracture as shown in Figure 5, suggesting a combination of intergranular and transgranular fracture. Further examinations of the fracture surfaces indicate that the cracking mode is mainly intergranular at $600{ }^{\circ} \mathrm{C}$, although cleavage steps can be seen as well (shown with arrows). The fraction of 
cleavage fracture is higher in the case of the RT tests as seen in figure 6(c)-(d). The frequent occurrence of transgranular cracking was surprising since the stress concentrations at the grain boundaries of the oxide layer would be expected to promote intergranular fracture. This tendency towards cleavage fracture was even more pronounced in the case of the flat microcantilevers (Figure 7).
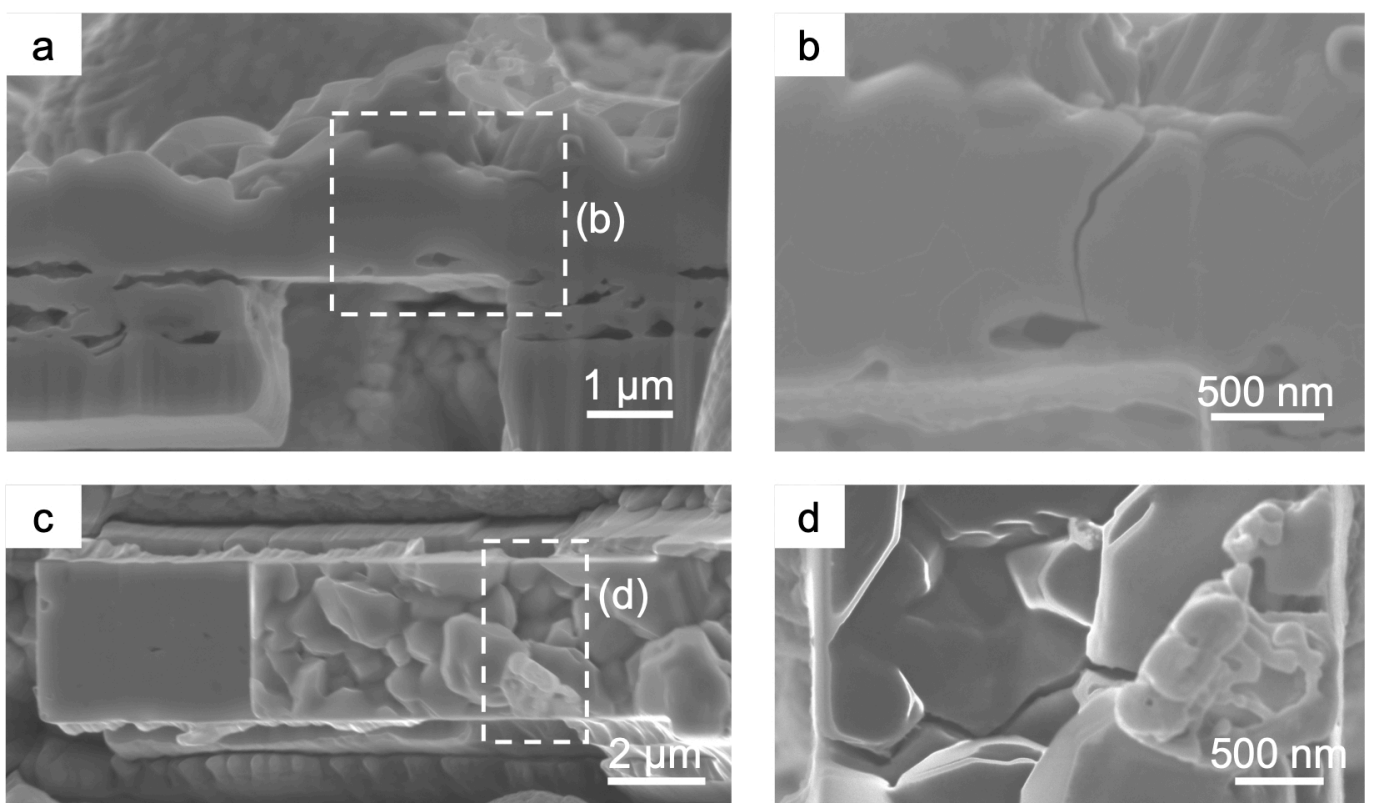

Figure 4: Different views of tested raw micro-cantilever. (a) side-view before testing; (b) side view of crack after testing from region highlighted in (a); (c) top-view before testing; (d) topview of crack after testing from highlighted region in (c). 

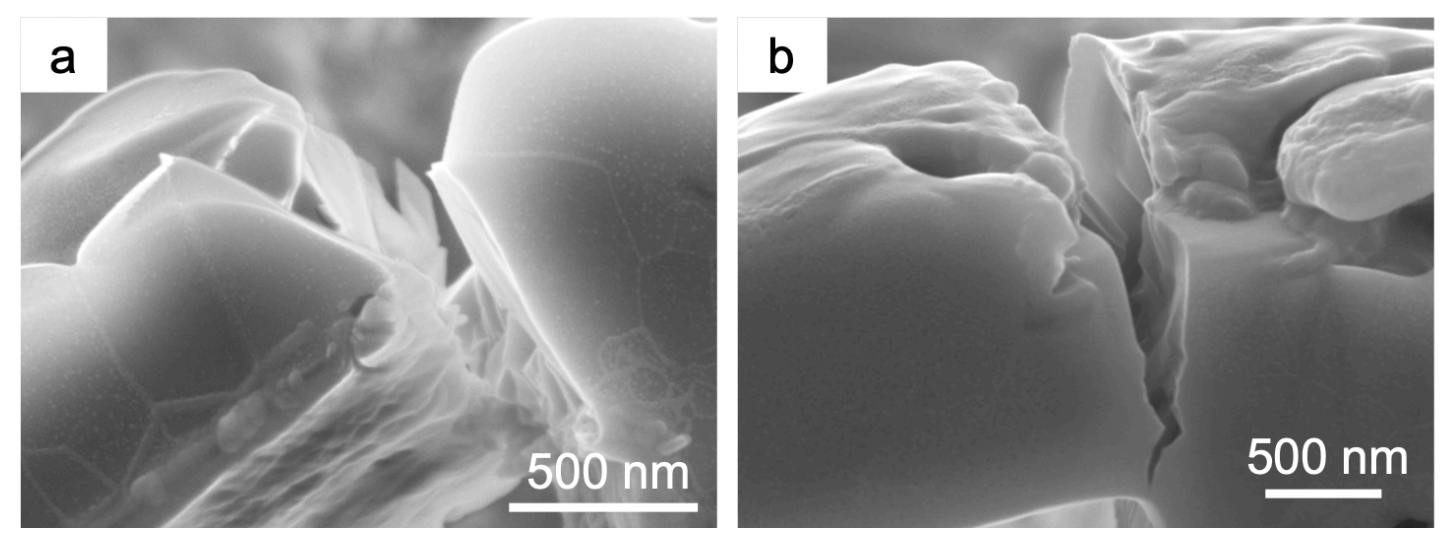

Figure 5: Cleavage fracture seen from side view of tested raw micro-cantilevers. (a) was tested at $600{ }^{\circ} \mathrm{C}$ and (b) at $\mathrm{RT}$.

It was possible to perform EBSD on the top surface of some flat micro-cantilevers before testing. Figure 8 shows the inverse pole figure map from the surface of one tested flat microcantilever with the position of the crack (determined from SEM images after testing) superimposed, which shows that the crack propagated in a transgranular manner. The orientations of the grains through which the crack propagated has been shown in the figure as well. The $c$ axis of the grains is at a small angle to the crack, which means that the cleavage plane could be one of the family of planes parallel to the $c$ axis [50], i.e. $\left\{\begin{array}{lll}1 & 0 & 1\end{array} 0\right\}$ or $\left\{\begin{array}{lll}1 & \overline{2} & 1\end{array} 0\right.$. Each family of plane has 3 equivalent planes, and plane traces of each plane (six in total) was compared with the path of the crack. The one that best fit with the angle of crack was considered as the probable cleavage plane for the particular grain. Table 1 shows the cleavage plane for each of the three grains of interest from Figure 8 . There is a good fit between the trace and the crack path for all the three highlighted grains, thus supporting the proposed cleavage mechanism. However, further analysis is needed, such as a 3D reconstruction of the fracture surface to allow for a proper correlation. 


\begin{tabular}{|c|c|c|}
\hline Grain position & Best fit & Second best fit \\
\hline A & $\left(\begin{array}{llll}1 & \overline{2} & 1 & 0\end{array}\right)$ & $\left(\begin{array}{llll}\overline{1} & 1 & 0 & 0\end{array}\right)$ \\
\hline B & $\left(\begin{array}{llll}\overline{1} & 1 & 0 & 0\end{array}\right)$ & $(\overline{2} 110)$ \\
\hline $\mathrm{C}$ & 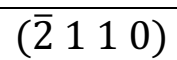 & $\left(\begin{array}{llll}\overline{1} & 1 & 0 & 0\end{array}\right)$ \\
\hline
\end{tabular}

Table 1: Cleavage planes for cracked grain from Figure 8.
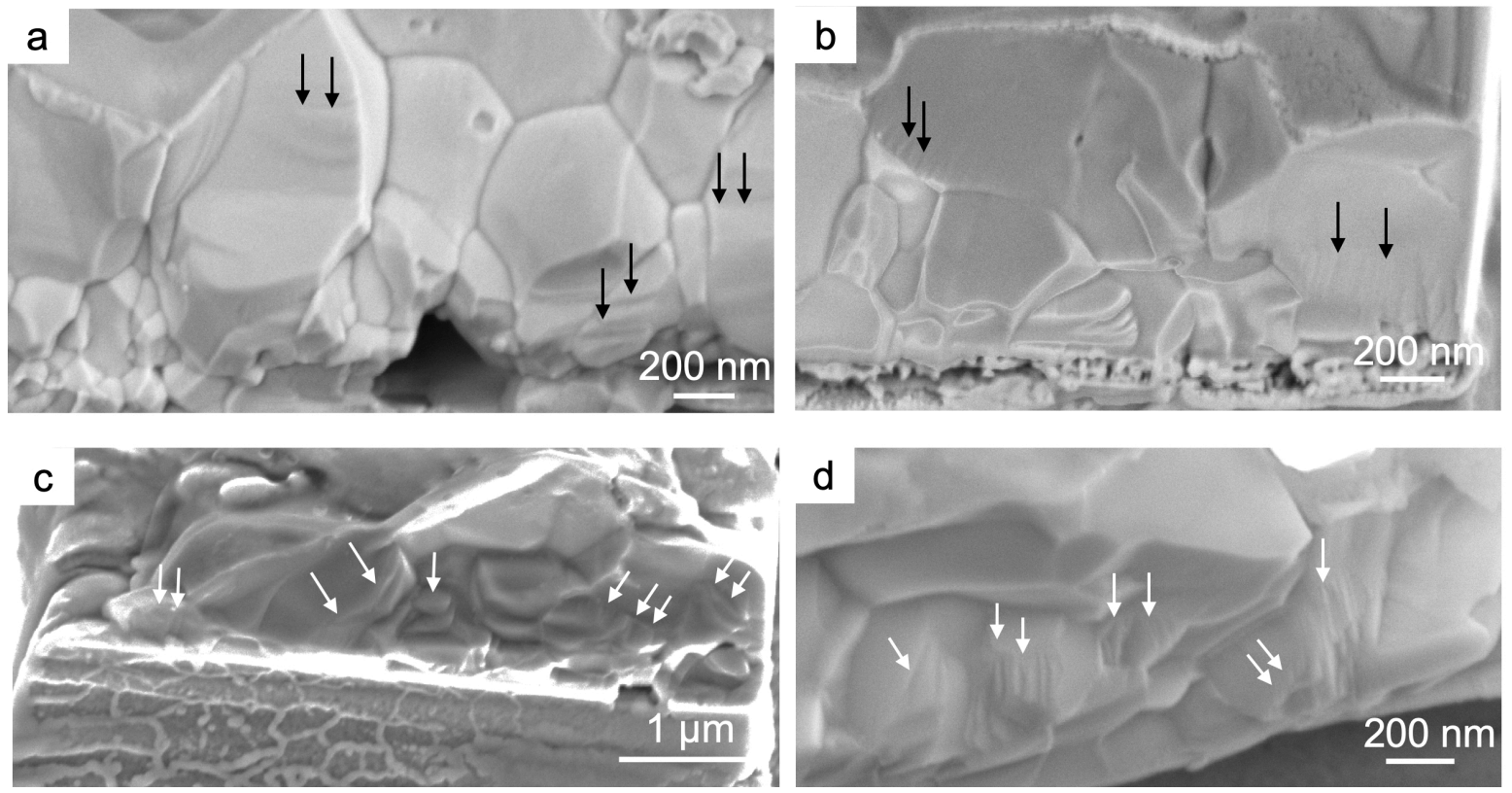

Figure 6: Fracture surfaces of tested raw micro-cantilevers. (a) and (b) are from $600{ }^{\circ} \mathrm{C}$ tests and, (c) and (d) are from RT tests. The arrows indicate the presence of river marks. 

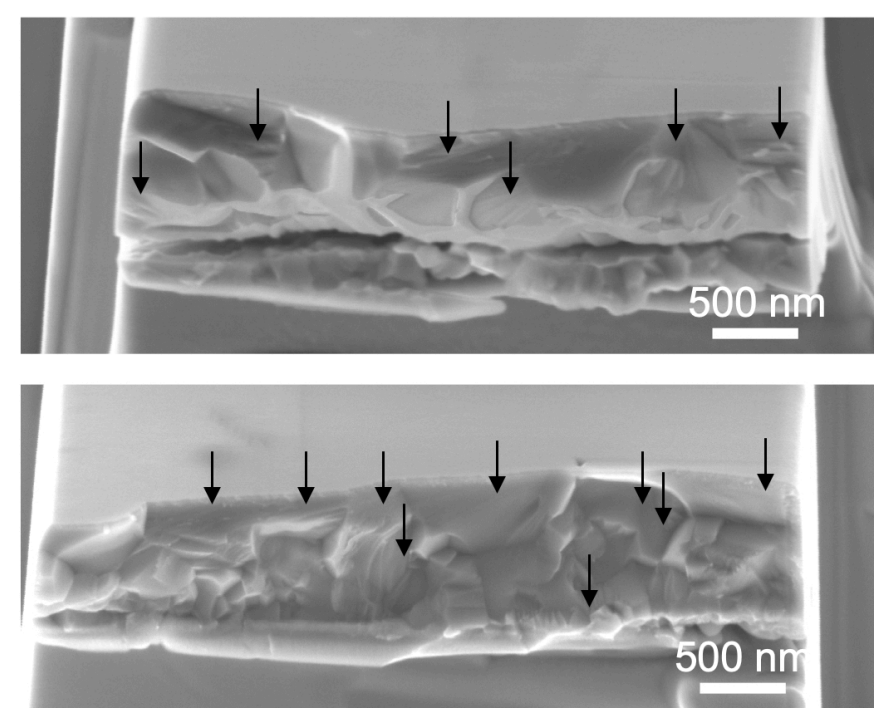

Figure 7: Examples of fracture surfaces of flat micro-cantilevers with arrows showing transgranular fracture.

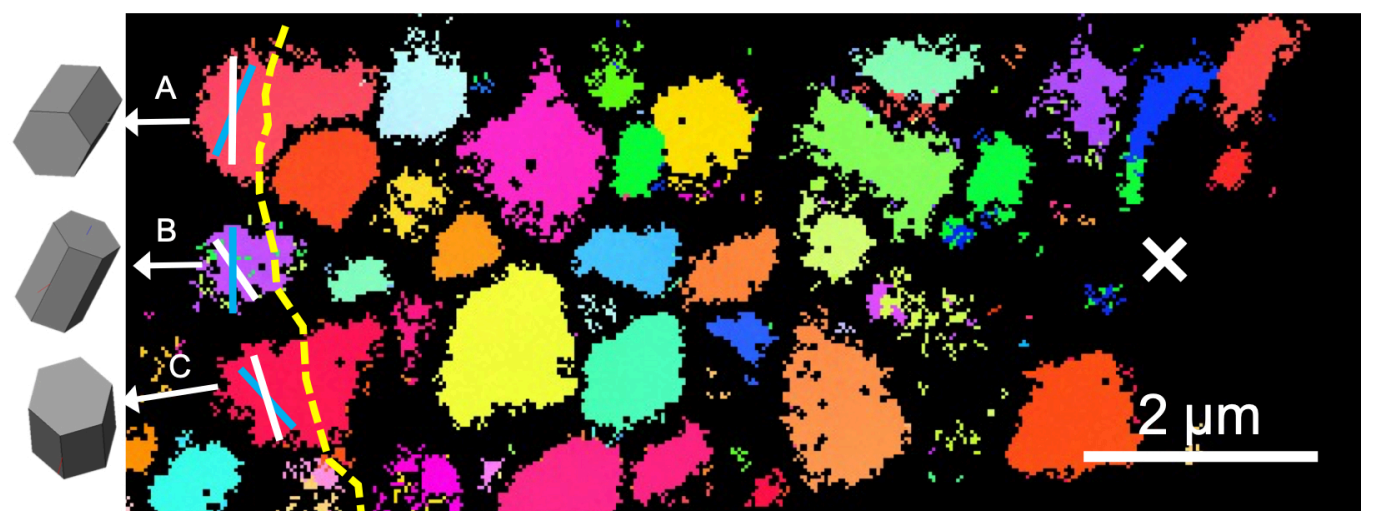

Figure 8: Inverse pole figure map of the top surface of a flat micro-cantilever. The loading point is shown towards the right with a cross. The yellow dotted line shows the crack path and the orientations of the grains with transgranular crack are shown as well. The white and blue line represents the plane traces of $\left\{\begin{array}{llll}1 & \overline{2} & 1 & 0\end{array}\right\}$ and $\left\{\begin{array}{llll}1 & 0 & \overline{1} & 0\end{array}\right\}$ respectively.

\section{Discussion}

\subsection{Fracture and mechanical properties of the oxide scale}

This approach of measuring mechanical response of thermally grown oxide scales provides more insight in to the mechanism of fracture when compared to the classical methods.

Simplified models such as the $\eta-c$ model [51] require parameters such as elastic modulus $(E)$, 
fracture toughness $\left(K_{\mathrm{IC}}\right)$ and physical defect size $(c)$ to be known to be able to predict the failure strains. In the case of grain boundary fracture model for superalloys [20], the fracture strain is required in order to predict the threshold crack growth rate. The approach presented here possesses the ability to provide data such as fracture strain and modulus for real systems and aid in generation of oxide failure models which in turn can produce life prediction models with better accuracy for high temperature materials. The current study shows that the fracture behaviour of thermally grown oxide scales is complex, and thorough and careful evaluations are required in order to generate meaningful data. The failure mechanism is not limited to intergranular cracking, but shows instances of transgranular cracking. This in turn calls for dedicated studies of both single grain cleavage and grain boundary fracture in chromia in future. Also, additional techniques are needed to bridge the gaps in the presented method. Parameters such as the orientation of fracture surface in cleaved grains as well as the physical defect size can be provided by 3D imaging and EBSD. The combination of FIB and SEM is a powerful tool to perform 3D which can take the method to the next step. Overall, such an approach shows that it is possible to obtain detailed information on the micro-mechanisms of fracture even at the scale of thermally grown oxide scales.

The micro-cantilever bending tests reveal several aspects of fracture properties associated with the oxide scale. By comparing the stress-strain curves of the $600{ }^{\circ} \mathrm{C}$ and $\mathrm{RT}$ raw tests, an immediate observation that can be made is that for all tests, the behaviour before fracture is elastic. Plasticity in oxides have been observed for $\mathrm{Al}_{2} \mathrm{O}_{3}$, which is also a corundum structured oxide, but for much higher temperatures [52], where creep is the dominant deformation mechanism and the strain rates are very low. It has also been seen in $\mathrm{Al}_{2} \mathrm{O}_{3}$ single crystals tested at room temperature using micropillar compression [35], where uniaxial stresses as high as $11 \mathrm{GPa}$ is required. Schütze et al. [53] have highlighted the requirements 
for plasticity in oxide scales, in which they state that for lower temperatures, the cracking in oxide scales start before reaching the stress levels required to activate the slip systems, in particular in the presence of tensile stresses. In addition, physical defects are also present in thermally grown oxides which initiate cracking before plasticity can occur. One of the possibilities is at high temperature where creep is active. But, the current temperature (600 ${ }^{\circ} \mathrm{C}$ ) is much less than $0.5 \mathrm{~T}_{\mathrm{m}}$ and therefore the possibilities for creep is minimum. Also, in presence of creep, the fracture strains at $600{ }^{\circ} \mathrm{C}$ would be expected to be higher than at RT, as observed by $\mathrm{Nagl}$ et al. [28] in $\mathrm{NiO}$ and $\mathrm{Fe}_{2} \mathrm{O}_{3}$.

In the present case the fracture is brittle, and the fracture mode at both $\mathrm{RT}$ and $600{ }^{\circ} \mathrm{C}$ has been shown to be mixed transgranular and intergranular, with a higher fraction of cleavage fracture in the RT tests. There is very limited quantitative data on fracture behaviour of chromia available in the literature, but existing results for alumina can be used for qualitative discussions. As in the present case, the fracture in polycrystalline alumina is generally of mixed transgranular and intergranular mode, and an increasing fraction of intergranular fracture with increasing temperature has been reported [54], consistent with the present results. Norton et al. [30] used micro-cantilever bending with notched and artificially flawed specimens in order to measure the fracture toughness associated with cleavage of different planes, as well as grain boundaries in polycrystalline alumina and in a diffusion bonded bicrystal. The fracture toughness for cleavage was found to be approximately a factor of two higher than for grain boundary fracture $\left(1.5 \mathrm{MPa} \mathrm{m}^{-1}\right.$ compared to $0.7 \mathrm{MPa} \mathrm{m}^{-1}$ obtained for grain boundaries in both diffusion bonded bi-crystal and polycrystal). Similarly, Yasuda et al. [55] measured a factor of two higher critical energy release rate for transgranular fracture in alumina, and showed a positive correlation between the fraction of transgranular cracking and fracture resistance. A compilation of the temperature dependence of the fracture toughness of 
single and polycrystalline alumina have shown that both decrease with temperature, consistent with the current observation of lower fracture strains at $600{ }^{\circ} \mathrm{C}[56]$. Further studies using simulations and specially designed fracture tests on ideal orientations will be able to shed even more light into the fracture mechanism.

As discussed previously, the scatter in stiffness for the raw micro-cantilevers can be attributed to various reasons such as geometric irregularities, anisotropy in the material, heterogenous distribution of porosity, etc. In order to evaluate the influence of such factors, some FE models were constructed considering some of the extreme cases. The details of the calculations are given in supplementary material, section F, and the results show that the stiffness can be almost halved in the most extreme cases. This is without accounting for uncertainties in the estimation of the average height of the oxide in the isolated part of the cantilevers, which is expected to have a significant effect. In addition to geometric factors, the testing is done on an oligo-crystalline material, which is anisotropic. This can be reflected in the variation of the mechanical data obtained. The anisotropy in elastic modulus ( $\left.E_{\max } / E_{\min }\right)$ for this oxide was obtained to be 1.6 from calculation detailed in section $\mathrm{E}$ of the supplementary material. This implies that the tested oxide could have a significant spread in modulus values depending on the orientations of the grains undergoing elastic deformation. These factors could account for the variations seen in the mechanical response of the tested specimens. However, from the tested flat micro-cantilevers, it can be observed that the scatter in the elastic modulus values is reduced in comparison with raw micro-cantilevers. Thus, the conclusion is that the scatter observed in mechanical response is mainly due to the geometric factors such as presence of stress concentrations and porosities. 


\subsection{Experimental considerations}

The surface condition is one factor that has to be studied in detail when FIB fabrication is involved. The micro-cantilever preparation involves initial rough milling to remove a larger volume of material (1000 $\mu \mathrm{m}^{3}$ or more), which leads to redeposition of the removed metal and oxide on the surface. This forms a thin layer of amorphous material on top of the surface oxide grains. This could influence the measured properties. This was analysed with the help of high-resolution transmission electron microscopy (HRTEM) and energy dispersive X-Ray spectroscopy (EDX) on an electron transparent sample prepared from region of microcantilever milling. It was seen that the thickness of the redeposition layer was roughly between 20-50 nm (for details, refer to section $\mathrm{G}$ in supplementary material). However, this thickness is not constant throughout and there is some variation in different oxide grains. The thickness of the redeposited layer is negligible in comparison to the oxide layer itself, and since the oxide roughness has a larger influence on the cracking mode through the formation of stress concentrations, no significant impact on the measured properties is expected. This layer is visible on top of the fracture surface in figure 6(a) and (b), but it doesn't seem to have affected the mode of fracture. Also, this layer is amorphous and will be full of defects, which would make it weaker than the oxide layer. An additional issue is occurrence of Ga implantation from the FIB milling on the properties. The contrast outlining the grain boundaries in Figure 5(a) is a result of Ga being ejected during the time at high temperature. Since only the side and bottom surfaces of the cantilever were exposed to Ga, and the implantation depth is very small (roughly $30 \mathrm{~nm}$ for normal incidence and $15 \mathrm{~nm}$ for gracing incidence, as seen from SRIM simulations [57]), this is not expected to have an impact on the fracture behaviour. Ga ejection can be seen also in Figure 6(c), this time on the bottom side of a cantilever tested at room temperature. This occurs since all cantilevers were milled on the same specimen, and consequently also the room temperature specimens were subjected to 
periods at $600{ }^{\circ} \mathrm{C}$, although after room temperature tests had been performed. The implantation of $\mathrm{Ga}$ is of more concern for the flat cantilevers, where the top surface is flattened using FIB milling. Although implantation is unavoidable in this case, the milling procedure was specifically designed to minimise the depth of the affected layer.

\section{Conclusions}

The current approach of using micro-cantilever bending in order to study fracture in thermally grown chromia has been shown to be highly effective in comparison to classical measurement methods. The estimated elastic modulus for the thermally grown oxide scales is in the range of 217 to $301 \mathrm{GPa}$, which agrees with the literature values. From the micro-cantilever bending experiments, new insights into the cracking behaviour has been obtained. Testing of raw asgrown scales resulted in significantly lower fracture strains at $600{ }^{\circ} \mathrm{C}$, compared to room temperature. The raw cantilevers fractured in a mixed inter- and transgranular manner, with a larger fraction of transgranular cracking at room temperature. The relatively large number of cleaved grains in the raw cantilevers is surprising, since the rough as-grown surface has pronounced stress concentrations at the grain boundaries in the "troughs". Removal of the surface roughness increases the tendency for transgranular fracture. The EBSD analyses were able to identify the possible cleavage planes for transgranular fracture, which points toward the fact that in addition to stress concentrations, the crystallographic orientation and texture plays a role in fracture, both at room temperature and $600{ }^{\circ} \mathrm{C}$. This hints at the need for dedicated single and bi-crystal testing in future so that the cracking mechanism can be studied in detail.

\section{Acknowledgments}

The authors would like to acknowledge the research funding from Vetenskapsrådet (Swedish research council) grant number 2015-04719. A.H.S.I. gratefully acknowledges Chalmers 
Research Fund for funding the high temperature experiments conducted at Empa, Swiss Federal laboratories for Materials Science and Technology, Thun, Switzerland. The room temperature experiments were conducted at Chalmers Materials Analysis Laboratory (CMAL), Gothenburg, Sweden. Dr. Olof Bäcke is acknowledged for his assistance with HRTEM.

\section{References}

[1] H.-J. Christ, Is Thermomechanical Fatigue Life Predictable?, Procedia Eng. 55 (2013) 181-190. doi:10.1016/j.proeng.2013.03.240.

[2] X. Hu, D. Shi, X. Yang, Thermomechanical fatigue experimental study on a notched directionally solidified Ni-base superalloy, Mater. Sci. Eng. A. 674 (2016) 451-458. doi:10.1016/j.msea.2016.08.030.

[3] P. Hancock, The influence of environment on the fatigue behaviour of superalloy components at high temperatures, Corros. Sci. 29 (1989) 657-671. doi:10.1016/0010938X(89)90106-6.

[4] M. Schütze, Modelling oxide scale fracture, Mater. High Temp. 22 (2005) 147-154. doi:10.1179/mht.2005.017.

[5] S. Cruchley, H.Y. Li, H.E. Evans, P. Bowen, D.J. Child, M.C. Hardy, The role of oxidation damage in fatigue crack initiation of an advanced Ni-based superalloy, Int. J. Fatigue. 81 (2015) 265-274. doi:10.1016/j.ijfatigue.2015.08.016.

[6] J.H. O’Hanlon, M.C. Hardy, D.J. Child, B. Foss, P.J. Withers, M.R. Bache, The effect of minimum dwell cycles on the environmental and fatigue response of RR1000, MATEC Web Conf. 14 (2014) 04003. doi:10.1051/matecconf/20141404003.

[7] V. Bauer, H.J. Christ, Thermomechanical fatigue behaviour of a third generation $\gamma$ TiAl intermetallic alloy, Intermetallics. 17 (2009) 370-377. 
doi:10.1016/j.intermet.2008.11.013.

[8] E. Andrieu, R. Molins, H. Ghonem, A. Pineau, Intergranular crack tip oxidation mechanism in a nickel-based superalloy, Mater. Sci. Eng. A. 154 (1992) 21-28.

[9] H. Ghonem, T. Nicholas, A. Pineau, Elevated Temperature Fatigue Crack Growth in Alloy 718-Part II: Effects of Environmental and Material Variables, Fatigue Fract. Engng Mater. Struct. 16 (1993) 577-590.

[10] M. Hörnqvist, T. Månsson, D. Gustafsson, High temperature fatigue crack growth in Alloy 718 - Effect of tensile hold times, Procedia Eng. 10 (2011) 147-152. doi:10.1016/j.proeng.2011.04.027.

[11] L. Viskari, M. Hörnqvist, K.L.L. Moore, Y. Cao, K. Stiller, Intergranular crack tip oxidation in a Ni-base superalloy, Acta Mater. 61 (2013) 3630-3639. doi:10.1016/j.actamat.2013.02.050.

[12] A.H.S. Iyer, K. Stiller, G. Leijon, H.C.M. Andersson-Östling, M. Hörnqvist Colliander, Influence of dwell time on fatigue crack propagation in Alloy 718 laser welds, Mater. Sci. Eng. A. 704 (2017) 440-447. doi:10.1016/j.msea.2017.08.049.

[13] P. Hancock, J.R. Nicholls, Application of fracture mechanics to failure of surface oxide scales, Mater. Sci. Technol. 4 (1988) 398-406. doi:10.1179/mst.1988.4.5.398.

[14] M. Schütze, Stresses and decohesion of oxide scales, Mater. Sci. Technol. 4 (1988) 407-414. doi:10.1179/mst.1988.4.5.407.

[15] J. Robertson, M.I. Manning, Limits to adherence of oxide scales, Mater. Sci. Technol. 6 (1990) 81-92. doi:10.1179/mst.1990.6.1.81.

[16] M. Schutze, S. Ito, W. Przybilla, H. Echsler, C. Bruns, Test methods and data on the mechanical properties of protective oxide scales, Mater. High Temp. 18 (2001) 39-50. doi:10.1179/mht.2001.004.

[17] M. Schütze, P.F. Tortorelli, I.G. Wright, Development of a Comprehensive Oxide 
Scale Failure Diagram, Oxid. Met. 73 (2010) 389-418. doi:10.1007/s11085-009-91857.

[18] M. Rudolphi, M. Schütze, Investigations for the Validation of the Defect Based Scale Failure Diagrams_-Part I: Nickel Oxide, Oxid. Met. 79 (2013) 167-177. doi:10.1007/s11085-012-9317-3.

[19] M. Rudolphi, M. Schütze, Investigations for the Validation of the Defect Based Scale Failure Diagrams - Part II: Extension of the Concept and Application to Nickel Oxide, Titanium Oxide and Iron Oxide, Oxid. Met. 84 (2015) 45-60. doi:10.1007/s11085-0159540-9.

[20] K.S. Chan, A Grain Boundary Fracture Model for Predicting Dynamic Embrittlement and Oxidation-Induced Cracking in Superalloys, Metall. Mater. Trans. A Phys. Metall. Mater. Sci. 46 (2015) 2491-2505. doi:10.1007/s11661-015-2860-1.

[21] M. Schütze, W.J. Quadakkers, Future Directions in the Field of High-Temperature Corrosion Research, Oxid. Met. 87 (2017) 681-704. doi:10.1007/s11085-017-9719-3.

[22] R.C. Hurst, M. Davies, P. Hancock, The determination of fracture strains of growing surface oxides on mild steel at high temperatures, Oxid. Met. 9 (1975) 161-169. doi:10.1007/BF00613230.

[23] M.M. Nagl, W.T. Evans, S.R.J. Saunders, D.J. Hall, Investigation of failure of brittle layers under compressive stresses using acoustic emission, Mater. Sci. Technol. 8 (1992) 1043-1050. doi:10.1179/mst.1992.8.11.1043.

[24] P.F. Tortorelli, J.R. Keiser, The use of depth-sensing submicron indentation testing to characterize the mechanical behavior of thin oxide scales, Scr. Metall. Mater. 25 (1991) 2339-2344. doi:10.1016/0956-716X(91)90026-W.

[25] P.F. Tortorelli, Mechanical properties of chromia scales, Le J. Phys. IV. 03 (1993) C9943-C9-949. doi:10.1051/jp4:1993997. 
[26] P.F. Tortorelli, S.R.J. Saunders, G. Shafirstein, D.J. Hall, Use of the mechanical properties microprobe for characterization of oxide scales, Mater. High Temp. 12 (1994) 95-101. doi:10.1080/09603409.1994.11689474.

[27] J.R. Nicholls, D.J. Hall, P.F. Tortorelli, Hardness and modulus measurements on oxide scales, Mater. High Temp. 12 (1994) 141-150. doi:10.1080/09603409.1994.11689480.

[28] M.M. Nagl, S.R.J. Saunders, W.T. Evans, D.J. Hall, The tensile failure of nickel oxide scales at ambient and at growth temperature, Corros. Sci. 35 (1993) 965-977. doi:10.1016/0010-938X(93)90315-8.

[29] F. Iqbal, J. Ast, M. Göken, K. Durst, In situ micro-cantilever tests to study fracture properties of NiAl single crystals, Acta Mater. 60 (2012) 1193-1200. doi:10.1016/j.actamat.2011.10.060.

[30] A.D. Norton, S. Falco, N. Young, J. Severs, R.I. Todd, Microcantilever investigation of fracture toughness and subcritical crack growth on the scale of the microstructure in A12O3, J. Eur. Ceram. Soc. 35 (2015) 4521-4533.

doi:10.1016/j.jeurceramsoc.2015.08.023.

[31] C. Motz, T. Schöberl, R. Pippan, Mechanical properties of micro-sized copper bending beams machined by the focused ion beam technique, Acta Mater. 53 (2005) 42694279. doi:10.1016/j.actamat.2005.05.036.

[32] J. Ast, M. N. Polyakov, G. Mohanty, J. Michler, X. Maeder, Interplay of stresses, plasticity at crack tips and small sample dimensions revealed by in-situ microcantilever tests in tungsten, Mater. Sci. Eng. A. 710 (2018) 400-412. doi:10.1016/j.msea.2017.10.096.

[33] Y. Kihara, T. Nagoshi, T.F.M. Chang, H. Hosoda, S. Tatsuo, M. Sone, Tensile behavior of micro-sized specimen made of single crystalline nickel, Mater. Lett. 153 (2015) 36-39. doi:10.1016/j.matlet.2015.03.119. 
[34] P.R. Howie, S. Korte, W.J. Clegg, Fracture modes in micropillar compression of brittle crystals, J. Mater. Res. 27 (2012) 141-151. doi:10.1557/jmr.2011.256.

[35] A. Montagne, S. Pathak, X. Maeder, J. Michler, Plasticity and fracture of sapphire at room temperature: Load-controlled microcompression of four different orientations, Ceram. Int. 40 (2014) 2083-2090. doi:10.1016/j.ceramint.2013.07.121.

[36] S. Korte-Kerzel, Microcompression of brittle and anisotropic crystals: recent advances and current challenges in studying plasticity in hard materials, MRS Commun. 7 (2017) 109-120. doi:10.1557/mrc.2017.15.

[37] D. Kiener, C. Motz, G. Dehm, Micro-compression testing: A critical discussion of experimental constraints, Mater. Sci. Eng. A. 505 (2009) 79-87. doi:10.1016/j.msea.2009.01.005.

[38] X. Zhao, R.M. Langford, J. Tan, P. Xiao, Mechanical properties of SiC coatings on spherical particles measured using the micro-beam method, Scr. Mater. 59 (2008) 3942. doi:10.1016/j.scriptamat.2008.02.022.

[39] S. Massl, W. Thomma, J. Keckes, R. Pippan, Investigation of fracture properties of magnetron-sputtered TiN films by means of a FIB-based cantilever bending technique, Acta Mater. 57 (2009) 1768-1776. doi:10.1016/j.actamat.2008.12.018.

[40] T.P. Weihs, S. Hong, J.C. Bravman, W.D. Nix, Mechanical deflection of cantilever microbeams: A new technique for testing the mechanical properties of thin films, J. Mater. Res. 3 (1988) 931-942. doi:10.1557/JMR.1988.0931.

[41] K. Matoy, T. Detzel, M. Müller, C. Motz, G. Dehm, Interface fracture properties of thin films studied by using the micro-cantilever deflection technique, Surf. Coatings Technol. 204 (2009) 878-881. doi:10.1016/j.surfcoat.2009.09.013.

[42] M.D. Abad, S. Parker, D. Frazer, M.R. 27002. pdfel. de Figueiredo, A. Lupinacci, K. Kikuchi, P. Hosemann, Evaluation of the Mechanical Properties of Naturally Grown 
Multilayered Oxides Formed on HCM12A Using Small Scale Mechanical Testing, Oxid. Met. 84 (2015) 211-231. doi:10.1007/s11085-015-9551-6.

[43] J. Dohr, D.E.J. Armstrong, E. Tarleton, T. Couvant, S. Lozano-Perez, The influence of surface oxides on the mechanical response of oxidized grain boundaries, Thin Solid Films. 632 (2017) 17-22. doi:10.1016/j.tsf.2017.03.060.

[44] A.H.S. Iyer, K. Stiller, M.H. Colliander, Room temperature plasticity in thermally grown sub-micron oxide scales revealed by micro-cantilever bending, Scr. Mater. 144 (2018) 9-12. doi:10.1016/j.scriptamat.2017.09.036.

[45] J.M. Wheeler, J. Michler, Invited Article: Indenter materials for high temperature nanoindentation, Rev. Sci. Instrum. 84 (2013) 101301. doi:10.1063/1.4824710.

[46] M. Conte, G. Mohanty, J.J. Schwiedrzik, J.M. Wheeler, B. Bellaton, J. Michler, N.X. Randall, Novel high temperature vacuum nanoindentation system with active surface referencing and non-contact heating for measurements up to $800{ }^{\circ} \mathrm{C}$, Rev. Sci. Instrum. 90 (2019) 045105. doi:10.1063/1.5029873.

[47] T.E.J. Edwards, F. Di Gioacchino, G. Mohanty, J. Wehrs, J. Michler, W.J. Clegg, Longitudinal twinning in a TiAl alloy at high temperature by in situ microcompression, Acta Mater. 148 (2018) 202-215. doi:10.1016/j.actamat.2018.01.007.

[48] Y. Wang, H. Fang, C.L. Zacherl, Z. Mei, S. Shang, L.Q. Chen, P.D. Jablonski, Z.K. Liu, First-principles lattice dynamics, thermodynamics, and elasticity of Cr2O3, Surf. Sci. 606 (2012) 1422-1425. doi:10.1016/j.susc.2012.05.006.

[49] R. Gaillac, P. Pullumbi, F.X. Coudert, ELATE: An open-source online application for analysis and visualization of elastic tensors, J. Phys. Condens. Matter. 28 (2016). doi:10.1088/0953-8984/28/27/275201.

[50] V. Pishchik, L.A. Lytvynov, E.R. Dobrovinskaya, Sapphire, Springer US, Boston, MA, 2009. doi:10.1007/978-0-387-85695-7. 
[51] M. Schütze, M. Rudolphi, Prediction of Mechanical Scale Failure - Current Status and Perspectives, Mater. Sci. Forum. 696 (2011) 138-143.

doi:10.4028/www.scientific.net/MSF.696.138.

[52] R.M. Cannon, W.H. Rhodes, A.H. Heuer, Plastic Deformation of Fine-Grained Alumina (A12O3): I, Interface-Controlled Diffusional Creep, J. Am. Ceram. Soc. 63 (1980) 46-53. doi:10.1111/j.1151-2916.1980.tb10648.x.

[53] M. Schütze, Plasticity of protective oxide scales, Mater. Sci. Technol. 6 (1990) 32-38. doi:10.1179/mst.1990.6.1.32.

[54] P.L. Gutshall, G.E. Gross, Observations and mechanisms of fracture in polycrystalline alumina, Eng. Fract. Mech. 1 (1969) 463-471. doi:10.1016/0013-7944(69)90005-8.

[55] K. Yasuda, J. Tatami, K. Asada, Y. Matsuo, S. Kimura, Influence of Crack Propagation Path on the Fracture Toughness of Polycrystalline A12O3, J. Ceram. Soc. Japan. 101 (1993) 1384-1389. doi:10.2109/jcersj.101.1384.

[56] I.D. Marinescu, M. Pruteanu, Deformation and Fracture of Ceramic Materials, in: Handb. Ceram. Grind. Polishing, Second Edi, Elsevier, 2015: pp. 50-66. doi:10.1016/B978-1-4557-7858-4.00002-9.

[57] J.F. Ziegler, M.D. Ziegler, J. Biersack, SRIM - The stopping and range of ions in matter (2010), Nucl. Instruments Methods Phys. Res. Sect. B Beam Interact. with Mater. Atoms. 268 (2010) 1818-1823. doi:10.1016/j.nimb.2010.02.091. 


\section{Microscale fracture of chromia scales}

Anand H.S. Iyer ${ }^{\mathrm{a}}$, Gaurav Mohanty ${ }^{\mathrm{b}, \mathrm{c}}$, Krystyna Stiller ${ }^{\mathrm{a}}$, Johann Michler ${ }^{\mathrm{c}}$, Magnus Hörnqvist Colliander ${ }^{\mathrm{a}}$

a Department of Physics, Chalmers University of Technology, Gothenburg, Sweden - 41296.

${ }^{\mathrm{b}}$ Materials Science and Environmental Engineering, Tampere University, 33014, Tampere, Finland.

${ }^{c}$ Empa, Swiss Federal Laboratories for Materials Science and Technology, Laboratory for Mechanics of Materials and Nanostructures, Feuerwerkerstrasse 39, 3602 Thun, Switzerland.

\section{$\underline{\text { Supplementary material }}$}

\section{A. Residual stress evaluation by Raman spectroscopy}

The oxide scales were checked for the presence of residual stresses with Raman spectroscopy mapping in a WITec Alpha 300R Raman microscope. A green laser with wavelength of 532 nm was used in the Raman spectroscopy studies. Area scans were performed in order to obtain an idea of the spatial distribution of residual stresses. Due to the difference in coefficient of thermal expansion between metal and the oxide, stresses develop in the scale when it cools to room temperature after exposure. In addition to that, lateral growth stresses exist within the scale, resulting in a net residual stress in the oxide scale. In the case of chromia, the Raman spectrum consists of $2 \mathrm{~A}_{1 \mathrm{~g}}$ and $4 \mathrm{E}_{\mathrm{g}}$ mode of vibrations [1], and the presence of stresses in the material causes a shift in the peak positions. For the $\mathrm{A}_{\mathrm{lg}}$ peak near $551 \mathrm{~cm}^{-1}$, which is the most intense peak, the shift is linearly proportional to the stress. The formula for stress (in GPa) is described by: $\sigma=-\Delta v \times 0.307$ [1], where $\Delta v$ is the difference in wave number between the constrained oxide and the reference, and 0.307 is the shift stress 
conversion coefficient. Figure S1 shows the Raman maps for the oxide scale. The residual stresses present in the oxide scale is compressive and as high as $1.8 \mathrm{GPa}$ in some regions. The regions that appear dark in the figure are regions with larger faceted grains of oxide. The spatial resolution of Raman area mapping is roughly $0.3 \mu \mathrm{m}$ and therefore the variation in stresses in clearer in the larger grains.

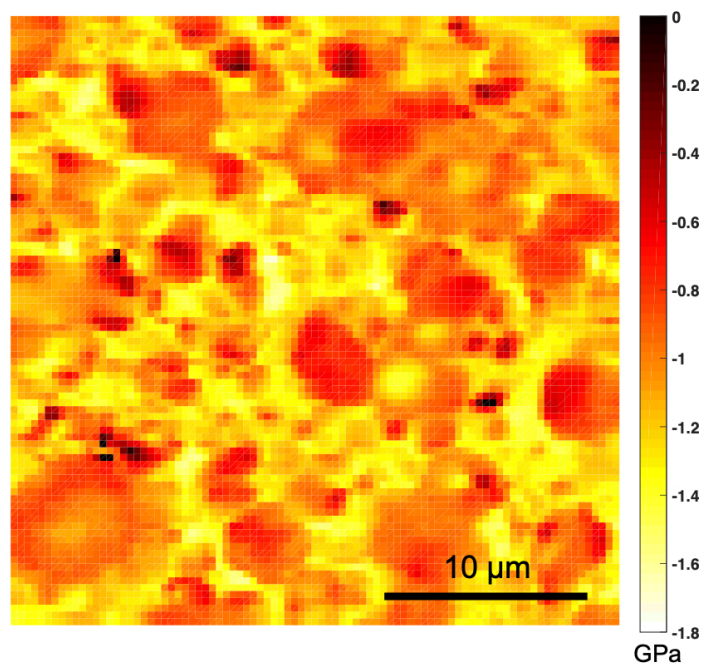

Figure S1: Raman map of the surface of oxide scale. Lighter regions have higher compressive residual stresses and darker regions have lower stresses. 


\section{B. Micro-cantilever dimensions}

Table S1: Dimensions of the FIB milled micro-cantilevers referred to as raw, where the top surface is untouched by ion-milling.

\begin{tabular}{|c|c|c|c|c|}
\hline SI No: & Length & Width & Oxide depth & Oxide span \\
& $\mathrm{L}(\mu \mathrm{m})$ & $\mathrm{w}(\mu \mathrm{m})$ & $\mathrm{h}(\mu \mathrm{m})$ & $\chi(\mu \mathrm{m})$ \\
\hline HT1 & $8.3 \pm 0.03$ & $3.23 \pm 0.06$ & $1.28 \pm 0.19$ & $2.94 \pm 0.06$ \\
\hline HT2 & $7.5 \pm 0.02$ & $2.94 \pm 0.08$ & $1.46 \pm 0.54$ & $2.88 \pm 0.02$ \\
\hline RT1 & $7.4 \pm 0.06$ & $5.4 \pm 0.16$ & $1.54 \pm 0.26$ & $2.96 \pm 0.05$ \\
\hline RT2 & $8.4 \pm 0.05$ & $5.28 \pm 0.11$ & $1.45 \pm 0.35$ & $2.9 \pm 0.02$ \\
\hline RT3 & $7.6 \pm 0.04$ & $4.29 \pm 0.07$ & $1.11 \pm 0.08$ & $2.98 \pm 0.05$ \\
\hline
\end{tabular}

Table S2: Dimensions of micro-cantilevers referred to as flat, where the oxide surface is made smooth by ion-milling.

\begin{tabular}{|c|c|c|c|c|}
\hline SI No: & Length & Width & Oxide depth & Oxide span \\
& $\mathrm{L}(\mu \mathrm{m})$ & $\mathrm{w}(\mu \mathrm{m})$ & $\mathrm{h}(\mu \mathrm{m})$ & $\chi(\mu \mathrm{m})$ \\
\hline F1 & $8.63 \pm 0.05$ & $4.33 \pm 0.02$ & $1.2 \pm 0.02$ & $2.94 \pm 0.03$ \\
\hline F2 & $7.39 \pm 0.04$ & $4.41 \pm 0.04$ & $1.35 \pm 0.04$ & $3.1 \pm 0.03$ \\
\hline F3 & $8.82 \pm 0.05$ & $4.3 \pm 0.03$ & $1.12 \pm 0.03$ & $2.98 \pm 0.05$ \\
\hline F4 & $7.62 \pm 0.04$ & $4.2 \pm 0.02$ & $0.92 \pm 0.02$ & $2.9 \pm 0.03$ \\
\hline
\end{tabular}

\section{Stress-strain calculation using FEM}

Since the geometry of the milled micro-cantilevers were complex, the conversion of forcedisplacement data to stress-strain was done with the help of a finite element model with same 
dimensions as the different micro-cantilevers. The surface roughness was not included and was considered as flat in the models. Figure S2 shows an example of the geometry used, consisting of half the cantilever and support with symmetry conditions enforced. A simple stationary study was performed on the model using dimensions of the different microcantilevers by application of an edge load, $F / 2$.

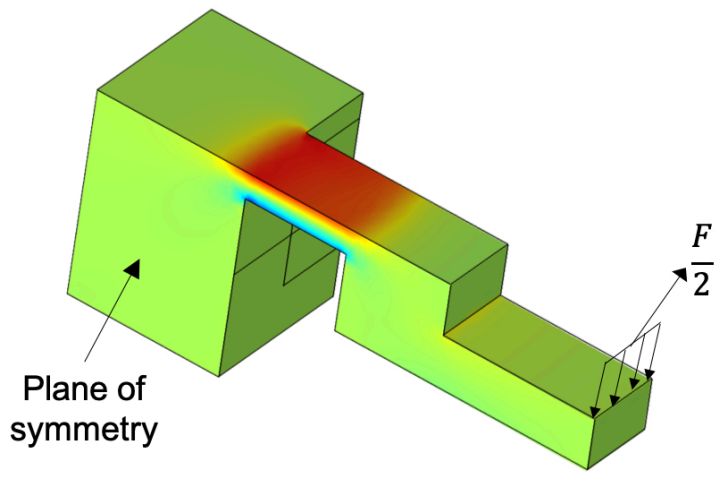

Figure S2: Geometry of micro-cantilever used in FEM.

The maximum stress $\left(\sigma_{\max }\right)$ and strain $\left(\varepsilon_{\max }\right)$ on the surface, and the displacement of the free end $(\delta)$ were evaluated and used in calculation of the geometric factors as follows:

$$
\begin{aligned}
& k_{\sigma}=\frac{\sigma_{\max }}{F} \\
& k_{\varepsilon}=\frac{\varepsilon_{\max }}{\delta}
\end{aligned}
$$

The geometric factors were used to convert the experimental force-displacement data into stress and strain.

\section{Elastic modulus calculation}

Bending tests were conducted on flat micro-cantilevers by applying small displacements to avoid fracture. Each micro-cantilever was bent for at least two different displacements, and 
each test consisted of three loading-unloading cycles in order to confirm repeatability. The force displacement data was converted to stress-strain by obtaining geometric constants from FEM (as in section C) and linear fitting in MATLAB was used to obtain the value of elastic modulus. Table S3 lists all the elastic modulus values obtained from the small displacement tests.

Table S3: Values of elastic modulus obtained from flat micro-cantilevers.

\begin{tabular}{|c|c|}
\hline SI No: & Elastic modulus (GPa) \\
\hline F1 & $257.3 \pm 19.8$ \\
\hline F2 & $217.5 \pm 15.7$ \\
\hline F3 & $301.3 \pm 15.1$ \\
\hline F4 & $271.6 \pm 19.7$ \\
\hline
\end{tabular}

\section{E. Anisotropy of elastic modulus}

In order to calculate the elastic anisotropy, the elastic stiffness in different crystallographic directions are required. In the case of $\mathrm{Cr}_{2} \mathrm{O}_{3}$, the following stiffness matrix was obtained from the values given in [2] considering rhombohedral symmetry:

$$
C=\left[\begin{array}{cccccc}
373 & 160 & 178 & -21 & 0 & 0 \\
160 & 373 & 160 & 21 & 0 & 0 \\
178 & 160 & 349 & 0 & 0 & 0 \\
-21 & 21 & 0 & 160 & 0 & 0 \\
0 & 0 & 0 & 0 & 160 & -21 \\
0 & 0 & 0 & 0 & -21 & 106.5
\end{array}\right]
$$

This matrix was used to calculate anisotropy with the aid of the web tool, ELATE [3] (http://progs.coudert.name/elate). 
The average elastic modulus (polycrystalline) was measured using Voigt averaging scheme, $E_{\text {avg }}=318.2 \mathrm{GPa}$.

Maximum value: $E_{\max }=394.1 \mathrm{GPa} .\left(\mathrm{hkl}=\left[\begin{array}{lll}0 & 0 & 1\end{array}\right]\right)$

Minimum value: $E_{\min }=241 \mathrm{GPa} .(\mathrm{hkl}=[0.670 .37-0.64])$

The anisotropy, which is the ratio of the maximum and minimum value is 1.63.

Figure S3 provides a visualisation of the anisotropy in elastic modulus $(E)$.

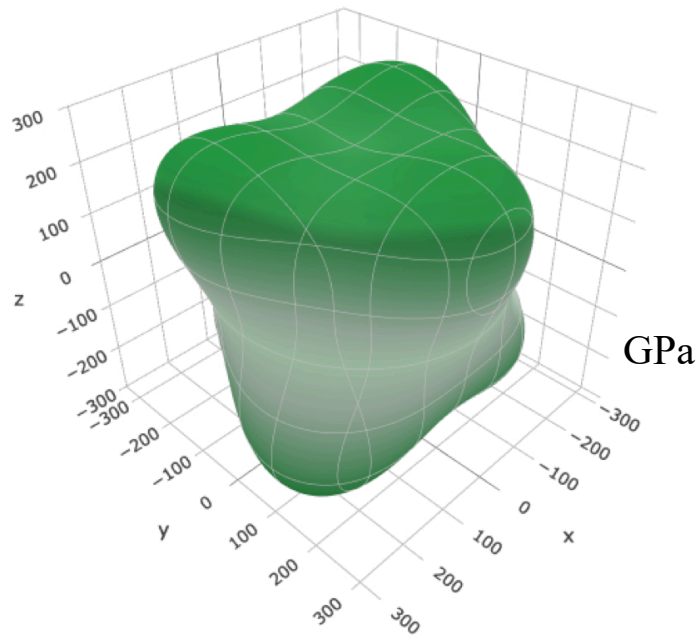

Figure S3: Visualisation of variation in elastic modulus for chromium oxide.

\section{F. Effect of geometric irregularities evaluated using FEM}

Effect of the presence of features such as stress concentrations and porosity in the oxide scale on its stiffness was investigated with the help of elastic FE models. Some extreme cases were chosen in order to demonstrate how much variations in stiffness are caused by notches, bumps and porosities. The following procedure was used in each case evaluated:

- A geometry was generated based on the situation considered, such as presence of notch or porosity.

- A small force was applied the resulting displacement $\left(\delta_{n}\right)$ was measured. 
- A reference cantilever was generated without any notches/porosity, where the height of the oxide part of the cantilever was calculated by keeping the projected area at the oxide part as constant (shown in Figure S4).

- A similar procedure was followed on the reference cantilever as well, in order to obtained the displacement $\left(\delta_{\text {ref }}\right)$.

- The effect of the notch on stiffness ratio is calculated as $\delta_{r e f} / \delta_{n}$

Note that only the surface roughness was considered when calculating the equivalent reference area. The porosity was neglected in order to obtain stiffness ratios corresponding to those that would be measured experimentally, since pores were not accounted for when estimating the average thicknesses in Tables S1 and S2, and in the case of internal porosity it would not be known. The different cases considered are presented in Table S5, showing stiffness reductions in the order of $15-48 \%$. Although the extreme case is unlikely in practice the results show that significant geometrical effects on the deduced elastic moduli can be expected.

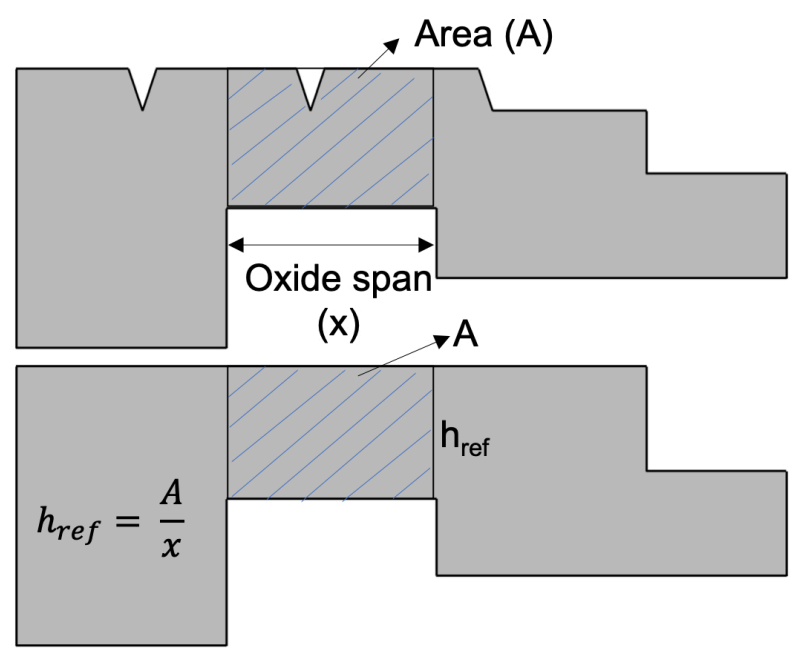

Figure S4: Illustration of how reference cantilever height is calculated. 
Table S5: Different cases considered for FEM. The stress scale shown for the first case is common for all cases.

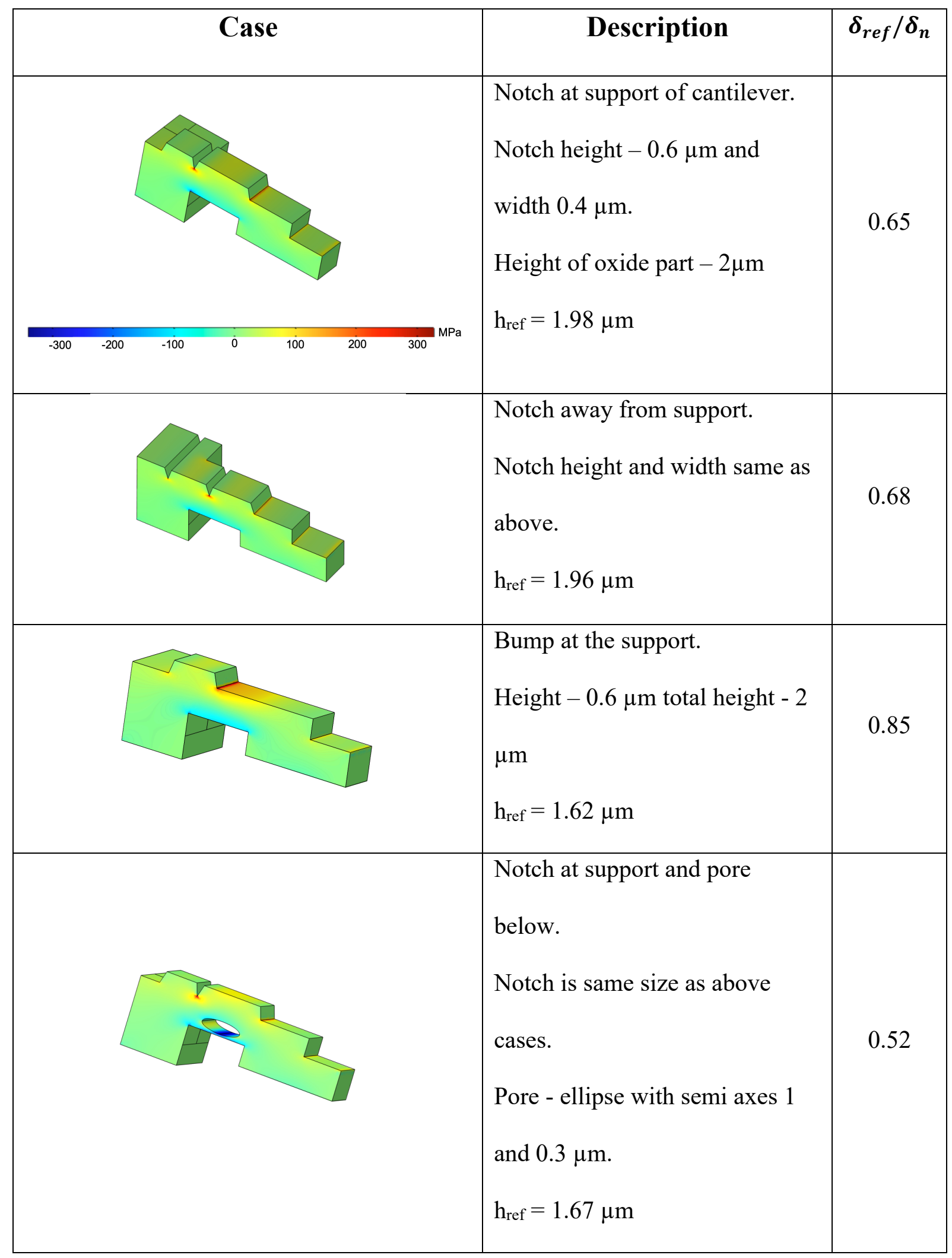




\begin{tabular}{|l|l|l|}
\hline & $\begin{array}{l}\text { Same as above but pore is } \\
\text { internal. }\end{array}$ & \\
Pore- ellipsoid with semi axes & 0.64 \\
$0.7,1$ and $0.3 \mu \mathrm{m}$. & \\
$\mathrm{h}_{\mathrm{ref}}=1.98 \mu \mathrm{m}$ & \\
\hline
\end{tabular}

\section{G. Analysis on redeposition layer}

Rough milling in FIB using high currents results in some redeposition on the surface of the oxide. In order to assess the presence of redeposition, A TEM lamella was prepared using FIB from a region near a milled micro-cantilever. High-resolution transmission electron microscopy (HRTEM) analysis was carried out in a FEI Titan 80-300 FEG TEM. High resolution imaging was performed in order to image the redeposition layer and assess its thickness as this layer would be amorphous, whereas the oxide grain would be crystalline. 


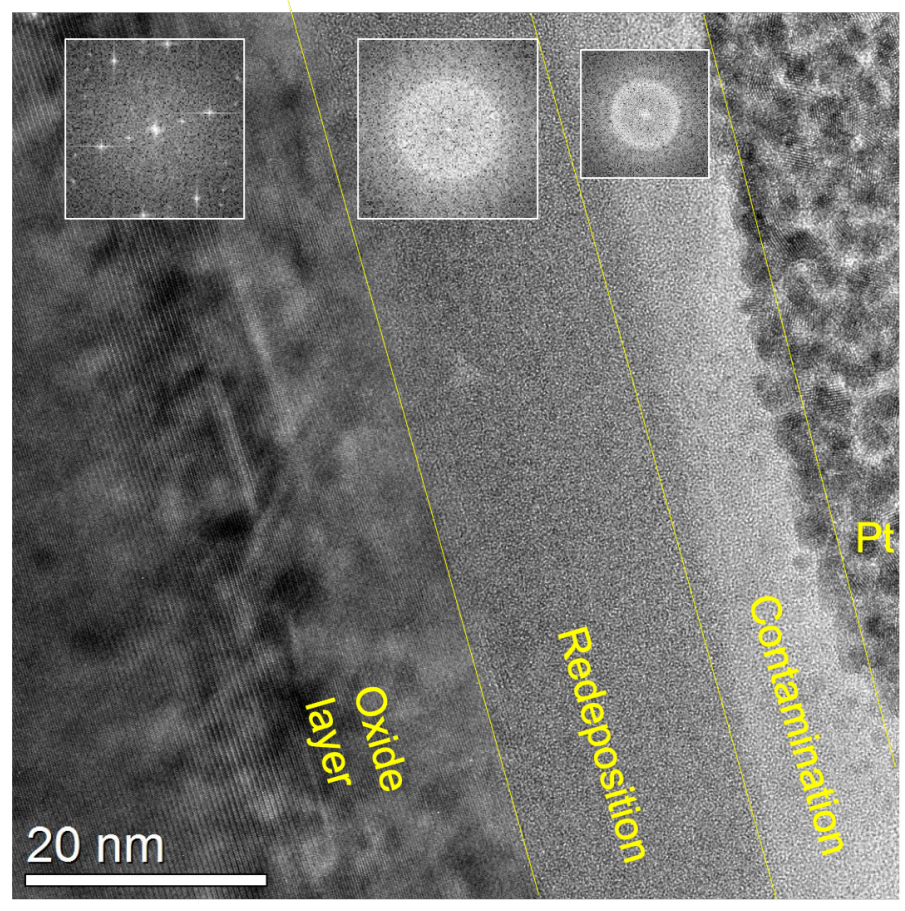

Figure S6: HRTEM image of chromium oxide layer with redeposition on top. The FFT is shown in inset for different layers.

Figure S6 shows the HRTEM image highlighting the different regions in the area of interest. From the fast fourier transforms (FFT) shown for different layers, it can be seen that the redeposition layer is amorphous and has a thickness of about $20 \mathrm{~nm}$. Chemical analysis was done in the form of an energy dispersive X-Ray spectroscopy (EDX) line scan. Figure S7 shows the results of the EDX analysis, where it can be seen that the redeposition layer has a chemical composition similar to the oxide, which is expected since the redeposited material consists of the oxide and metal particles. The redeposition layer shows the presence of gallium in addition to chromium and oxygen, which also aids in highlighting the redeposited region. 

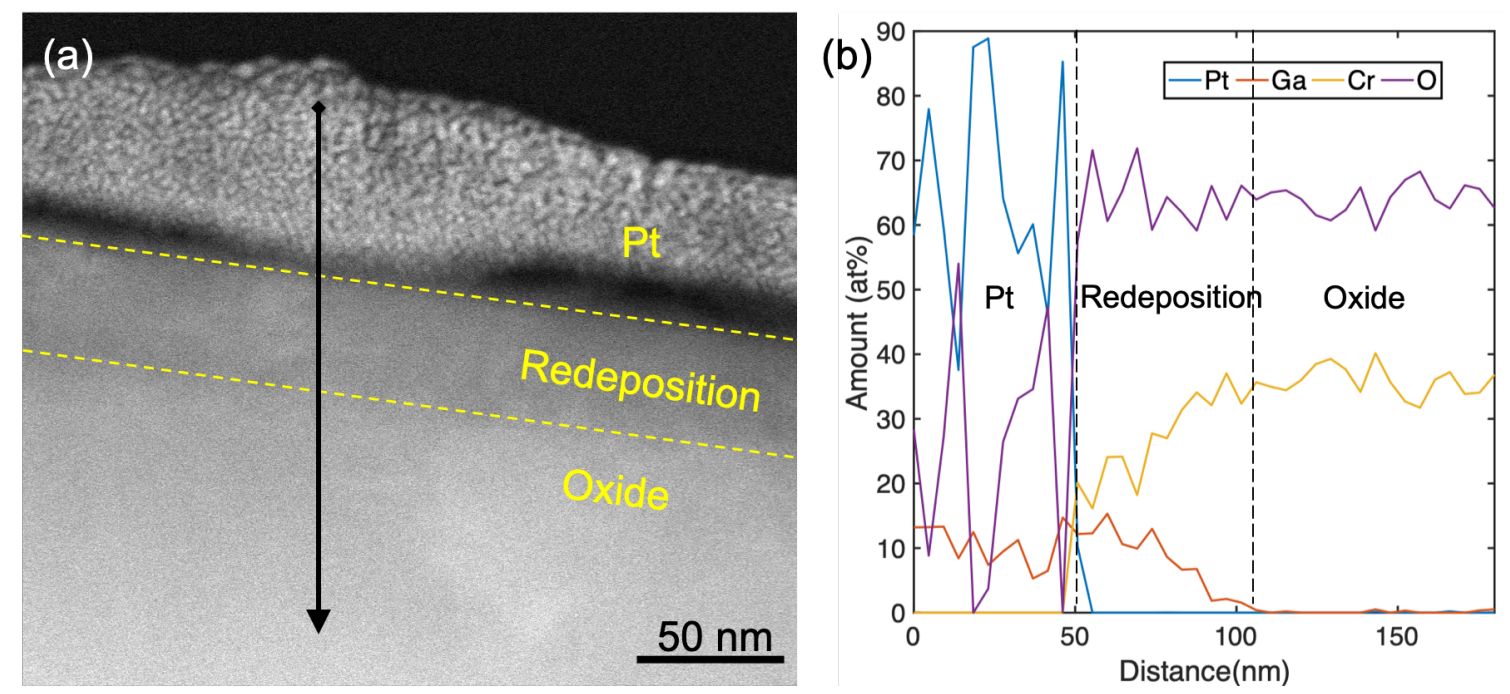

Figure S7: (a) High angle annular dark field (HAADF) scanning transmission electron microscopy (STEM) image of oxide layer with different regions highlighted; (b) results of EDX line scan from the black line shown in (a).

\section{References}

[1] J. Mougin, T. Le Bihan, G. Lucazeau, High-pressure study of Cr2O3 obtained by hightemperature oxidation by X-ray diffraction and Raman spectroscopy, J. Phys. Chem. Solids. 62 (2001) 553-563. doi:10.1016/S0022-3697(00)00215-8.

[2] Y. Wang, H. Fang, C.L. Zacherl, Z. Mei, S. Shang, L.Q. Chen, P.D. Jablonski, Z.K. Liu, First-principles lattice dynamics, thermodynamics, and elasticity of $\mathrm{Cr} 2 \mathrm{O} 3$, Surf. Sci. 606 (2012) 1422-1425. doi:10.1016/j.susc.2012.05.006.

[3] R. Gaillac, P. Pullumbi, F.X. Coudert, ELATE: An open-source online application for analysis and visualization of elastic tensors, J. Phys. Condens. Matter. 28 (2016). doi:10.1088/0953-8984/28/27/275201. 